\title{
Top-of-Atmosphere Shortwave Anisotropy over Liquid Clouds: Sensitivity to Clouds' Microphysical Structure and Cloud-Topped Moisture
}

\author{
Florian Tornow ${ }^{1, *}$, René Preusker ${ }^{1}$, Carlos Domenech ${ }^{2}$, Cintia K. Carbajal Henken ${ }^{1}$, \\ Sören Testorp ${ }^{1}$ and Jürgen Fischer ${ }^{1}$ \\ 1 Institute for Space Sciences, Freie Universität Berlin, Carl-Heinrich-Becker-Weg 6-10, \\ 12065 Berlin, Germany; rene.preusker@fu-berlin.de (R.P.); cintia.carbajal@wew.fu-berlin.de (C.K.C.H.); \\ soeren.testorp@wew.fu-berlin.de (S.T.); juergen.fischer@fu-berlin.de (J.F.) \\ 2 GMV Innovating Solutions, Isaac Newton 11, 28760 Tres Cantos (Madrid), Spain; cdomenech@gmv.com \\ * Correspondence: florian.tornow@fu-berlin.de; Tel.: +49-30-838-75012
}

Received: 5 June 2018; Accepted: 6 July 2018; Published: 10 July 2018

\begin{abstract}
We investigated whether Top-of-Atmosphere Shortwave (TOA SW) anisotropy-essential to convert satellite-based instantaneous TOA SW radiance measurements into TOA SW fluxes-is sensitive to cloud-top effective radii and cloud-topped water vapor. Using several years of CERES SSF Edition 4 data-filtered for overcast, horizontally homogeneous, low-level and single-layer clouds of cloud optical thickness 10-as well as broadband radiative transfer simulations, we built refined empirical Angular Distribution Models (ADMs). The ADMs showed that anisotropy fluctuated particularly around the cloud bow and cloud glory (up to $2.9-8.0 \%$ ) for various effective radii and at highest and lowest viewing zenith angles under varying amounts of cloud-topped moisture (up to 1.3-6.4\%). As a result, flux estimates from refined ADMs differed from CERES estimates by up to $20 \mathrm{~W} \mathrm{~m}^{-2}$ at particular combinations of viewing and illumination geometry. Applied to CERES cross-track observation of January and July 2007-utilized to generate global radiation budget climatologies for benchmark comparisons with global climate models-we found that such differences between refined and CERES ADMs introduced large-scale biases of $1-2 \mathrm{~W} \mathrm{~m}^{-2}$ and on regional levels of up to $10 \mathrm{~W} \mathrm{~m}^{-2}$. Such biases could be attributed in part to low cloud-top effective radii (about $8 \mu \mathrm{m})$ and low cloud-topped water vapor $\left(1.7 \mathrm{~kg} \mathrm{~m}^{-2}\right)$ and in part to an inopportune correlation of viewing and illumination conditions with temporally varying effective radii and cloud-topped moisture, which failed to compensate towards vanishing flux bias. This work may help avoid sampling biases due to discrepancies between individual samples and the median cloud-top effective radii and cloud-top moisture conditions represented in current ADMs.
\end{abstract}

Keywords: CERES; energy budget; broadband radiative transfer simulations; cloud effective radius; upper-tropospheric humidity

\section{Introduction}

Radiative fluxes-leaving the Earth-Atmosphere system through Top-of-Atmosphere (TOA) and inferred from satellite measurements-are a key variable in diagnosing the system's current energy balance and — when observed repeatedly— to assess the radiative effects of clouds and aerosols (e.g., [1]). Clouds impact the energy balance through: (1) the emission of terrestrial radiation-largely regulated through their cloud-top temperature; and (2) the reflection of solar radiation-mainly driven by their cloud micro- and macrophysical properties. Marine boundary layer clouds are predominantly found in regions of large-scale subsidence and reflect solar radiation-where a much darker ocean would otherwise absorb-while emitting terrestrial radiation similar to cloud-free conditions (since their low 
altitude leads to a near-surface temperature at cloud-top) (e.g., [2]). This radiative response affects the prediction of tropical clouds in a future climate [3], and large uncertainties in the radiative feedback of low-level clouds arise from inaccurately predicted properties in general circulation models [4]. A main factor altering cloud properties is aerosols. In the presence of aerosols, cloud liquid water may distribute over more numerous and smaller droplets which crucially alters cloud optical properties and ultimately affects solar reflection [5]. Marine boundary layer clouds are especially exposed to and affected by various aerosol types (e.g., [6]), including biomass burning (e.g., [7,8]) from nearby continents as well as volcanic emissions and exhaust from ships (e.g., [9-11]). The covariance of aerosol with meteorological conditions, such as humidity above clouds (hereafter referred to as cloud-topped moisture) complicates the assessment of cloud-aerosol interaction (e.g., [12]).

To convert instantaneous TOA broadband radiance measurements into corresponding TOA fluxes, satellite missions $[13,14]$ have been relying on CERES ADMs (latest version "CERES SSF Edition 4" as described in [15]). The conversion for solar radiances to fluxes above clouds is-apart from viewing and illumination conditions-a function of cloud phase and cloud optical depth. The conversion factor, anisotropy, is resolved by viewing geometry (relative azimuth angles $\phi$ and viewing zenith angle $\theta_{v}$ ) given a certain illumination geometry (solar zenith angle $\theta_{s}$ ). Anisotropy is mainly characterized by the cloud glory (the direct reflection back to the sun), the cloud bow (the direction of reflection at a scattering angle of about $140-145^{\circ}$ ), and higher intensity at larger $\theta_{v}$ in the forward-scattering direction. In theory, features of the scattering phase function, such as cloud bow and glory, should correspond to the size distribution of cloud droplets. This correlation is illustrated in Figure 1. Stratocumulus clouds and their cloud-aerosol interaction should distribute reflected solar radiation differently depending on their droplet size distribution (given a constant cloud optical depth). Additionally, low clouds can have vast amounts of water vapor aloft. Such absorbing gas (acting mainly beyond $0.8 \mu \mathrm{m}$ ) should have a stronger effect on upwelling radiances at larger $\theta_{v}$ than at smaller ones due to respective atmospheric path lengths. Accordingly, anisotropy should be dependent on levels of water vapor.

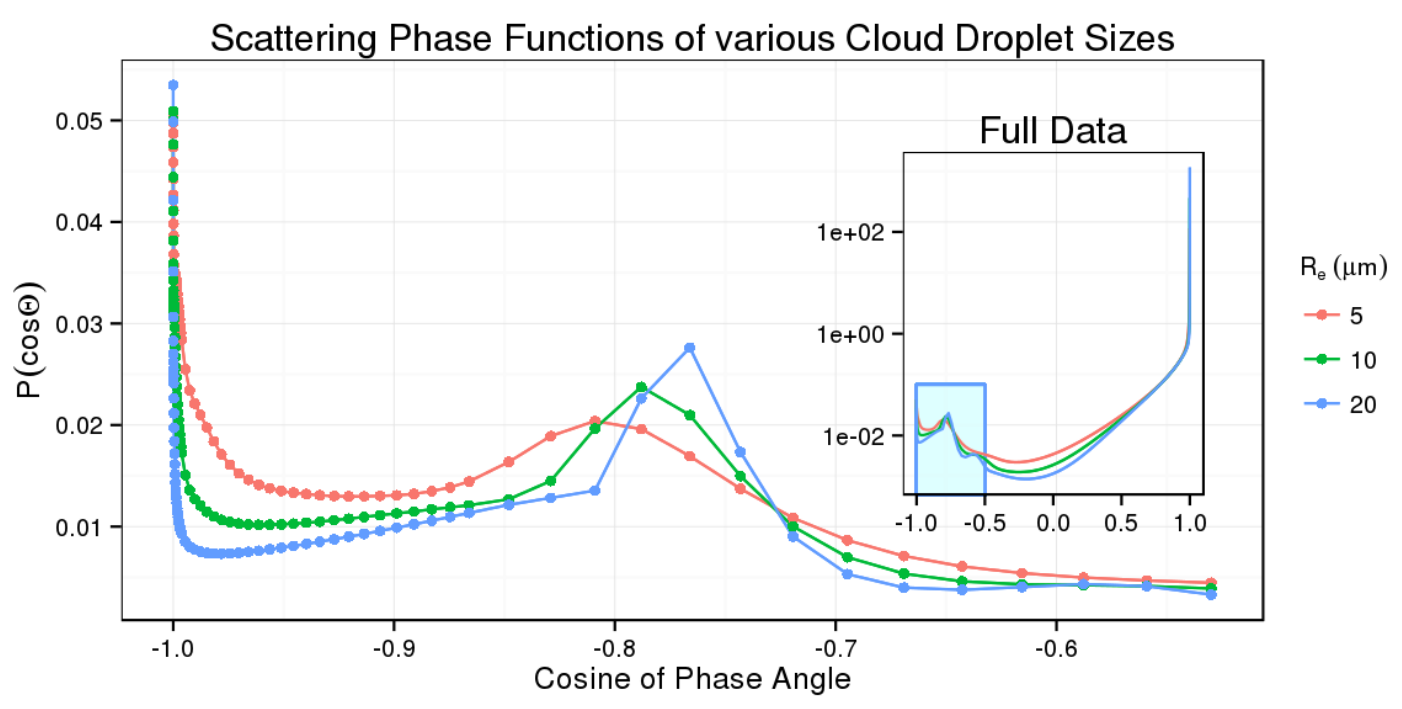

Figure 1. Broadband phase functions for three different cloud droplet effective radii $R_{\mathcal{e}}$. Phase functions were spectrally integrated over the solar regime $(0.25-4.00 \mu \mathrm{m})$ and are based on Mie calculation in spectral subintervals, assuming a Gamma-Hansen distribution with an effective variance of 0.11. Contributions from each subinterval were weighted by corresponding spectral cloud extinction and solar constant. Note that the y-axis of the inset is logarithmic, while the main plot is shown in linear scale. 
In this study, we hypothesize that TOA SW anisotropy changes significantly with cloud microphysical properties, represented through the cloud-top effective radius, and amount of moisture above clouds, represented through cloud-topped water vapor. Using several years of CERES SSF Edition 4 data, we extracted footprints of low-level and single-layer clouds above ocean which are overcast, horizontally homogeneous, and had mean cloud optical depth of about 10 (Section 2.1). As shown in Section 2.3, we built new empirical ADMs using CERES-measured SW reflectances, MODIS-retrieved cloud-top effective radii, and estimates of cloud-topped water vapor (Section 2.2). In Section 3, we demonstrate that refined ADMs had a sensitivity to above effective radii and water vapor, and that missing such sensitivity resulted in regional and systematic underestimation of TOA SW fluxes. Finally, Section 4 discusses results.

\section{Material and Methods}

\subsection{TOA SW Reflectances}

\subsubsection{CERES Edition 4 SSF}

We obtained TOA SW reflectances $(0.3-5.0 \mu \mathrm{m})$ from CERES SSF Edition 4 [15]. Measurements were realized by CERES instruments [16] on board Aqua and Terra satellites and operating in two modes: the Rotating Azimuth Plane Scan (RAPS) mode (performed periodically during 2000-2005) and cross-track scan mode (2007). CERES footprints covered areas of about $20 \mathrm{~km}$ diameter at nadir. For $\theta_{v}$ of up to $69.5^{\circ}$, all footprints were collocated with MODIS imagery as well as products derived from the CERES/MODIS cloud algorithms based on [17]. Cloud information on MODIS pixel-basis was used for statistics across CERES footprints, taking into account the instrument's point spread function [16].

We screened footprints for conditions typical of marine stratocumulus by selecting mean cloud-top pressures between 700 and $1000 \mathrm{hPa}$ of single-layer clouds, a mean logarithmic cloud optical thickness $\tilde{\tau}=\exp (\overline{\log \tau})$ of 10 (permitting values between 9.75 and 10.25) as well as ocean surface fractions greater $95 \%$. We also screened overcast conditions (selecting cloud fraction $f \geq 99 \%$ ), and cases free of horizontal inhomogeneity $[18,19]$ by using footprints of $v>10$, where $v=\bar{\tau}^{2} / \sigma(\tau)^{2}, \bar{\tau}$ is the mean optical thickness and $\sigma(\tau)$ is the standard deviation of mean cloud optical thickness. Table 1 summarizes extracted footprints after screening.

Table 1. A list of CERES footprints, obtained after screening for low-level and single-layer clouds, overcast conditions, a cloud optical depth of 10, and cases free of horizontal inhomogeneity: in total, $2,470,099$ footprints.

\begin{tabular}{cccc}
\hline \multicolumn{4}{c}{ No. of CERES Footprints } \\
\hline Year & Terra & Aqua & Mode \\
\hline & (FM1 and FM2) & (FM3 and FM4) \\
\hline 2000 & 192,604 & $/$ & RAPS \\
2001 & 259,810 & $/$ & RAPS \\
2002 & 278,305 & 85,745 & RAPS \\
2003 & 266,966 & 223,979 & RAPS \\
2004 & 274,189 & 27,6981 & RAPS \\
2005 & 4730 & 62,213 & RAPS \\
2006 & $/$ & $/$ & $/$ \\
2007 & 273,343 & 271,234 & cross-track \\
\hline
\end{tabular}

\subsubsection{Broadband Radiative Transfer Simulations}

To supplement observations, we simulated TOA SW reflectances using the radiative transfer code MOMO Matrix-Operator Model [20]. Simulations covered the solar spectrum between 0.25 and 
$4.00 \mu \mathrm{m}$ through 53 spectral subintervals, chosen such that water spectral refractive indices changed near-linearly with wavelength. For each subinterval, non-correlated k-binning [21] produced-based on HITRAN-2008 database [22] $-\mathcal{O}\left(10^{1}-10^{3}\right) \mathrm{k}$-terms to represent gaseous absorption. We chose about 80 vertical layers between 0 and $120 \mathrm{~km}$, vertically resolving the lowest $2 \mathrm{~km}$ of atmosphere at $25-100 \mathrm{~m}$ (except for cloud-top and cloud-topped inversion, resolved at $5 \mathrm{~m}$ ), 2-5 km altitude at $500 \mathrm{~m}$, and $5-20 \mathrm{~km}$ at $2.5 \mathrm{~km}$ intervals. The choice of 70 Fourier terms allowed for an azimuthal resolution of $6^{\circ} . \theta_{s}$ (and likewise $\theta_{v}$ ) were resolved at 35 angles, most of them listed in Table 2, Column 1 . We used an isotropic ocean surface and Mie-calculated phase functions to represent scattering and absorption by clouds droplets in each vertical layer, and assumed a Gamma-Hansen droplet size distribution [23].

To cover realistic ranges of cloud-topped water vapor in simulations, we extracted four representative temperature and moisture profiles from radiosonde observations (Figure 2), covering $3.2-20.1 \mathrm{~kg} \mathrm{~m}^{-2}$ of cloud-topped water vapor. We found St. Helena often exposed to the South-East Atlantic stratocumulus deck and therefore believe that vertical radiosonde profiles represent moisture conditions of the mid to upper troposphere in the larger subsidence area well. The shape of the moisture profiles had minor impact on simulated TOA SW reflectances as variation of pressure and temperature broadened water vapor absorption lines was small compared to the variation in mass absorption. Concentrations of other gases (i.e., $\mathrm{CO}_{2}, \mathrm{O}_{3}, \mathrm{~N}_{2} \mathrm{O}, \mathrm{CO}, \mathrm{CH}_{4}, \mathrm{O}_{2}$, and $\mathrm{NO}$ ) correspond to the AFGL (Air Force Geophysics Laboratory) midlatitude summer atmospheric profile [24]. To explore potential scenarios of cloud vertical profiles which resemble stratocumulus clouds of optical thickness 10 and were subject to weaker or stronger cloud-aerosol interaction, we used the adiabatic theory (e.g., [25]). Adiabatic clouds increase linearly in liquid water content (LWC) from cloud base to top and have a vertically constant cloud droplet number concentration. Sub-adiabatic conditions (i.e., an adiabaticity of $<1$ ) capture the intrusion of dry air from aloft and this reduces the linear slope of LWC accordingly. Figure 3 shows the resulting 13 scenarios of adiabatic clouds, assuming an adiabaticity of 0.6. All cloud scenarios had a cloud top-pressure of $875 \mathrm{hPa}$.

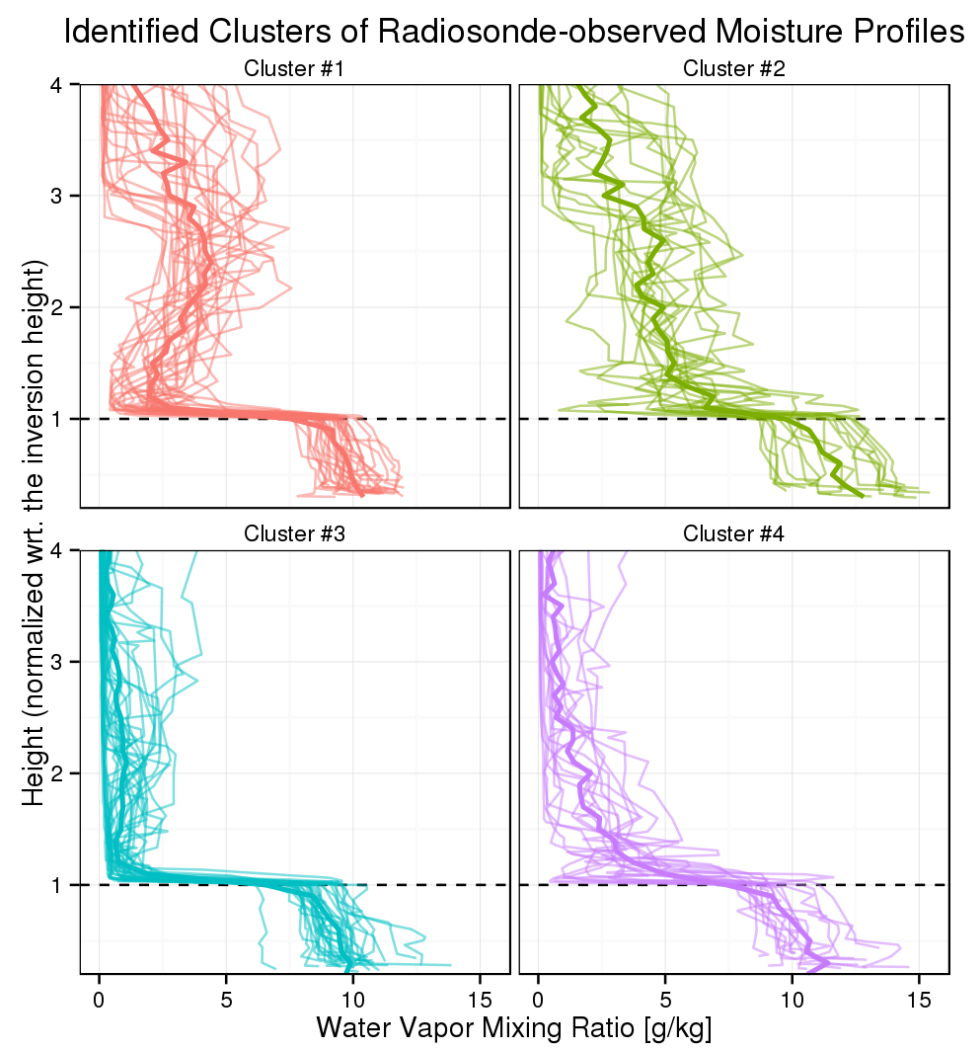

Figure 2. Four main clusters of vertical moisture profiles as observed during cloudy days (ascertained 
through MODIS imagery from Aqua and Terra satellites) over 12 months (August 2016 to July 2017) of radiosonde observations on St. Helena (http://catalogue.ceda.ac.uk/uuid/ c6fccd62a8ad4d9ea35fb825c3968910). Clusters were obtained through k-means clustering based on mixing ratios at three different heights (normalized with respect to the cloud-top): 1.2 as well as mean values of 1.4-1.6 and 2.3-2.7. Cloud-top levels were inferred from highest observed vertical level (within the lowest $2.5 \mathrm{~km}$ ) with a relative humidity larger than $85 \%$. For simulations, we used temperature and moisture profiles of the nearest neighbor to each cluster center.

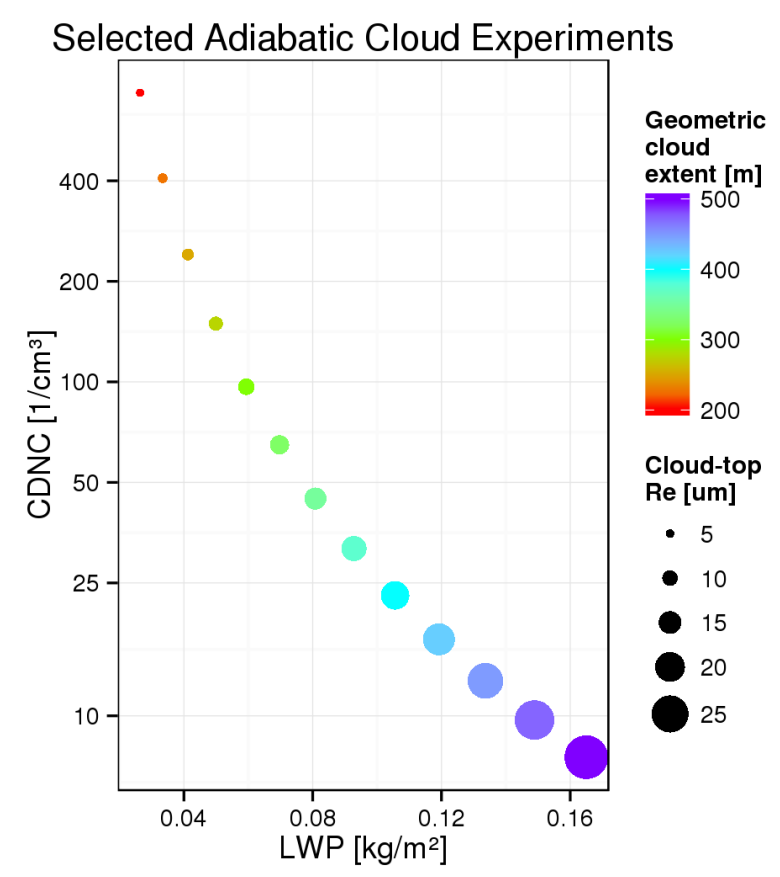

Figure 3. The setup of thirteen adiabatic cloud experiments. Each experiment arrived at a cloud optical depth of 10 and a cloud top pressure of $875 \mathrm{hPa}$. Across experiments, both liquid water path (LWP; $x$-axis) and cloud-droplet number concentration (CDNC; $y$-axis) varied. Accordingly, geometric extent (shown in color) and profiles of cloud droplet effective radii (represented by cloud-top effective radius shown in dot size) changed.

\subsection{Cloud-Topped Water Vapor}

To approximate the vertical column of water vapor located above marine low-level clouds, we used the following variables: precipitable water $P W$, surface skin temperature $T_{S}$ and surface pressure $P_{S}$-all provided by the Goddard Earth Observing System (GEOS) [26] version 5.4.1 and collocated to CERES footprints-as well as MODIS mean cloud top and cloud base pressure $\left(P_{C T}\right.$ and $P_{C B}$, respectively). All fields were included in CERES Edition 4 SSF (introduced in Section 2.1).

First, we approximated the amount of water in the cloud-topped boundary layer. Taking the $T_{S}$ and the dry-adiabatic lapse rate, we derived the temperature at cloud base level $T_{C B}$. Applying the relation by Bolton [27] (shown in Equation (1)), we determined the saturation vapor pressure $e_{S}$ at cloud base temperature (here, $T_{C B}$ in ${ }^{\circ} \mathrm{C}$ ) and then (in Equation (2)) the mixing ratio $r$. $W_{w}$ and $W_{\text {air }}$ are molecular weights of water and dry air, respectively.

$$
\begin{gathered}
e_{S}=6.112 \exp \left(\frac{17.67 T_{C B}}{T_{C B}+243.5}\right) \\
r=\frac{e_{S}}{P_{C B}} \frac{W_{w}}{W_{\text {air }}} 10^{-3}
\end{gathered}
$$


Assuming well-mixed conditions and thus a constant $r$ within the cloud-topped boundary layer, we integrated the vertical column of water vapor between surface and cloud-top. Finally, we subtracted the boundary layer integral from $P W$ to gain the vertical column of cloud-topped water vapor CTWV (as shown in Equation (3) where $g$ is the gravitational constant and $\rho_{w}$ is the water density).

$$
C T W V=P W-\frac{1}{g \rho_{w}} \int_{P_{S}}^{P_{C T}} r d p
$$

With regard to Figure 2, boundary layers rarely had a vertically constant mixing ratio and therefore violated the assumption of being well-mixed. By using the ratio at cloud base, we potentially compensated an underestimation in the cloud-free boundary layer with an overestimation between cloud base and cloud top. Our methodology, additionally, depended on a correct vertical position of the cloud. In the case of under- or overestimation of cloud base and top, the effect on errors in cloud-topped water vapor should, however, be regularizing: for example, an overestimation in cloud base and top height would result in lower boundary layer mixing ratios (as the cloud base temperature was erroneously lower) which would be integrated over a higher boundary layer. We mimicked a cloud base and top underestimation of $50 \mathrm{hPa}$ and found a median offset of $-0.5 \mathrm{~kg} \mathrm{~m}^{-2}(-7.6 \%)$ in cloud-topped moisture. Negative values in cloud-topped water vapor (found in $13 \%$ of all footprints) were set to zero.

\subsection{Angular Distribution Models}

The general strategy to estimate instantaneous fluxes $F$ from observed radiances $I_{0}$ is to empirically learn-per scene type and per illumination geometry $\theta_{s}$-the directional intensity of upwelling radiances with respect to the prevalent upwelling flux. Therefore, the upward hemisphere (resolved by $\theta_{v}$ and $\phi$ ) is discretized. Observations are sorted into angular bins. Once all bins of the upward hemisphere are filled, fluxes $(\hat{F})$ are estimated through the hemispheric integral of mean radiances $\hat{I}$ from each bin. The last step is to infer on anisotropy $R$ (Equation (4)).

$$
R\left(\theta_{s}, \theta_{v}, \phi\right)=\frac{\pi \hat{I}\left(\theta_{s}, \theta_{v}, \phi\right)}{F\left(\hat{\theta}_{s}\right)}=\frac{\pi \hat{I}\left(\theta_{s}, \theta_{v}, \phi\right)}{\int_{0}^{2 \pi} \int_{0}^{\pi / 2} \hat{I}\left(\theta_{s}, \theta_{v}, \phi\right) d \theta_{v} d \phi}
$$

A new radiance observation $I_{0}$ can be converted into an instantaneous flux $F$, as shown in Equation (5).

$$
F\left(\theta_{s}\right)=\frac{\pi I_{o}\left(\theta_{s}, \theta_{v}, \phi\right)}{R\left(\theta_{s}, \theta_{v}, \phi\right)}
$$

In CERES SSF Edition 4, liquid clouds over ocean were treated as a single scene type. To consider stark intensity changes of upwelling radiances with cloud fraction and cloud optical depth, collected radiances of each angular bin (resolved by $2^{\circ}$ in $\theta_{v}$ and $\phi$ ) served to produce a sigmoidal fit linking $\hat{I}$ and $\ln (f \tilde{\tau})$. ADMs were therefore based on hemispheric integrals of sigmoidal fits. In effect, resulting anisotropies are a function of $\ln (f \tilde{\tau})$. In this study, $f \approx 100 \%$ and $\tilde{\tau} \approx 10$. Essentially, CERES TOA SW anisotropy—per angular bin and per discrete illumination geometry (resolved at $2^{\circ}$ )—remained constant.

We produced new ADMs (hereafter referred to as "refined ADMs") by incorporating intensity changes of upwelling instantaneous reflectance $\rho_{o}$ with cloud-top effective radius $R_{e}$ and cloud-topped moisture CTWV. The use of MODIS-retrieved $R_{e}$ based on $3.7 \mu \mathrm{m}$ radiances (instead of $1.6 \mu \mathrm{m}$ or $2.1 \mu \mathrm{m}$ ) ensured lower and less systematic uncertainties [28,29]. We produced a linear model per angular bin and discrete illumination geometry of the following form (with least-square estimates $a, b$, and $c$ ):

$$
\ln \rho_{o}\left(\theta_{s}, \theta_{v}, \phi\right)=a+b \cdot \ln R_{e}+c \cdot C T W V
$$

An example is shown in Figure 4. Naturally, the spread in $\tilde{\tau}$ added variability in $\rho_{0}$. We assumed that the linear fit was unaffected. This assumption required that $\tilde{\tau}$ was uncorrelated to $\ln R_{e}$ and 
$C T W V$, and we found no indication of such correlation. Incorporating all available data points could bias the least square estimate towards the bulk of the data and leave extremes (such as particularly small $R_{e}$ and low $C T W V$, and vice versa, as seen in Figure 4) unaccounted for. Angular bins containing few observations hindered strategies involving subsampling or computation of representatives such that the parameter space spanned by $R_{e}, C T W V$, and $\rho_{o}$ was covered homogeneously.

Similar to the CERES approach, we integrated TOA albedos as a function of linear models and inferred on TOA SW anisotropies. We produced a look-up table by applying linear models to $R_{e}$ between 5 and $25 \mu \mathrm{m}$ (by steps of $1 \mu \mathrm{m}$ ) as well as CTWV between 0 and $40 \mathrm{~kg} \mathrm{~m}^{-2}$ (by increments of $2 \mathrm{~kg} \mathrm{~m}^{-2}$ ).

In the case of insufficient CERES observations within a bin (less than 10 or samples with a spread in $R_{e}$ of smaller than $10 \mu \mathrm{m}$ ), we added reflectances from broadband radiative transfer simulations (introduced in Section 2.1) to complement CERES observations. This was generally necessary for $\theta_{v}$ beyond $70^{\circ}$ and occasionally for some bins at particularly low or high $\theta_{s}$ (as listed in Table 2).

Table 2. A list summarizing the availability and nature of CERES footprints per increment of $\theta_{s}$. To fill angular bins (resolved by $\phi$ and $\theta_{v}$; here shown for $\theta_{v}$ between 0 and $70^{\circ}$ ) within the upward hemisphere, CERES footprints (numbers shown in Column 2) were in part supplemented by broadband simulations (fraction of bins receiving support shown in Column 3). Collected CERES samples varied considerably in cloud-top effective radius (Column 4; showing minimum to maximum of medians for each angular bin) and cloud-topped water vapour (Column 5).

\begin{tabular}{|c|c|c|c|c|}
\hline \multirow[b]{2}{*}{$\theta_{s}\left(^{\circ}\right)$} & \multirow{2}{*}{$\begin{array}{c}\text { CERES } \\
\text { Footprints }\end{array}$} & \multirow{2}{*}{$\begin{array}{c}\text { Bins Supplemented } \\
\text { with Simulations (\%) }\end{array}$} & \multicolumn{2}{|c|}{ Min.-Max. in Angular Bin Medians of } \\
\hline & & & Cloud-Top $R_{e}(\mu \mathrm{m})$ & Cloud-Topped WV $\left(\mathrm{kg} \mathrm{m}^{-2}\right)$ \\
\hline 16.2 & 16,144 & 33.3 & $5.9-26.2$ & $0.0-30.8$ \\
\hline 18.8 & 29,636 & 14.4 & $6.8-17.6$ & $0.0-27.2$ \\
\hline 21.4 & 42,413 & 7.1 & $6.8-14.8$ & $0.0-20.7$ \\
\hline 23.9 & 53,459 & 2.6 & $7.7-14.0$ & $0.0-16.7$ \\
\hline 26.5 & 70,327 & 1.5 & $9.1-16.5$ & $0.0-15.6$ \\
\hline 29.1 & 84,465 & 1.0 & $9.1-15.3$ & $0.0-16.3$ \\
\hline 31.7 & 92,215 & 0.8 & $8.8-15.5$ & $0.0-14.3$ \\
\hline 34.3 & 103,819 & 0.6 & $8.6-13.3$ & $0.0-13.3$ \\
\hline 36.9 & 110,576 & 0.3 & $9.5-13.9$ & $0.9-12.0$ \\
\hline 39.5 & 111,249 & 0.3 & $9.3-14.1$ & $0.4-12.7$ \\
\hline 42.1 & 113,933 & 0.2 & $10.1-14.1$ & $0.0-12.3$ \\
\hline 44.7 & 110,230 & 0.2 & $10.4-14.1$ & $0.2-8.6$ \\
\hline 47.3 & 108,844 & 0.8 & $10.7-15.4$ & $1.0-8.7$ \\
\hline 49.9 & 103,208 & 0.2 & $10.9-15.1$ & $0.0-9.2$ \\
\hline 52.4 & 97,595 & 0.6 & $11.1-17.3$ & $0.3-7.9$ \\
\hline 55.0 & 85,986 & 0.8 & $9.5-16.1$ & $0.0-8.9$ \\
\hline 57.6 & 75,292 & 1.3 & $11.0-15.4$ & $0.0-9.2$ \\
\hline 60.2 & 67,078 & 1.0 & $10.7-16.5$ & $0.0-7.8$ \\
\hline 62.8 & 58,011 & 1.8 & $11.5-18.0$ & $0.0-10.5$ \\
\hline 65.4 & 45,071 & 2.4 & $7.9-17.5$ & $0.0-10.3$ \\
\hline 68.0 & 55,063 & 2.1 & $12.2-20.1$ & $0.0-7.4$ \\
\hline 70.6 & 43,824 & 2.6 & $10.0-19.6$ & $0.0-7.7$ \\
\hline 73.2 & 37,792 & 4.0 & $11.7-21.9$ & $0.0-12.0$ \\
\hline 75.8 & 30,961 & 6.7 & $8.9-19.7$ & $0.0-18.0$ \\
\hline 78.3 & 22,864 & 14.1 & $10.8-22.5$ & $0.0-16.6$ \\
\hline 80.9 & 16,282 & 25.5 & $9.2-22.5$ & $0.0-16.6$ \\
\hline
\end{tabular}




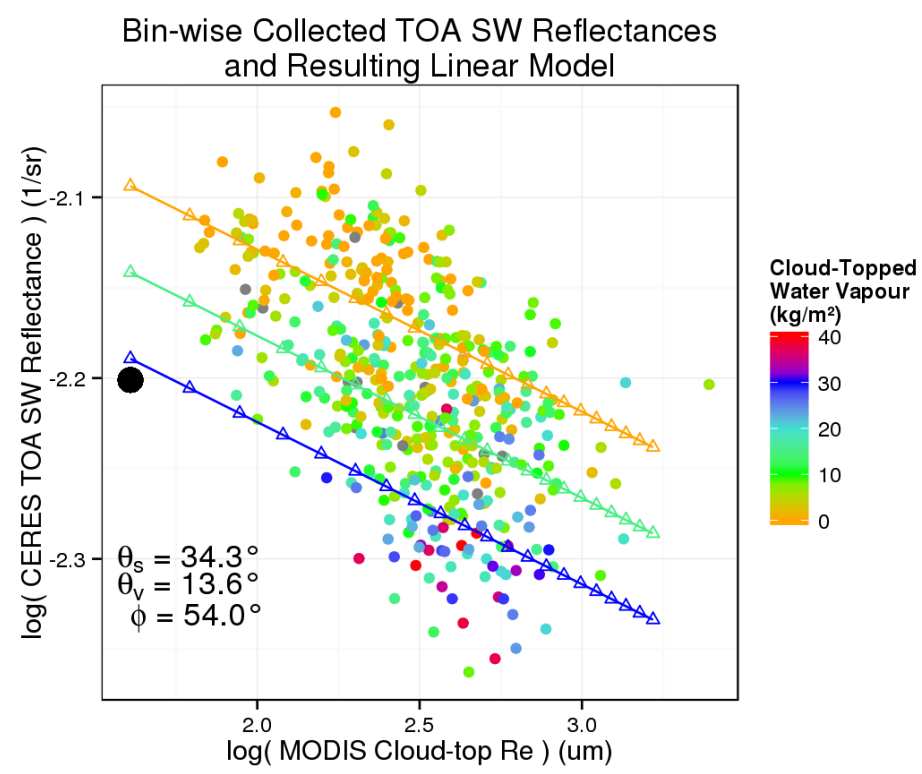

Figure 4. For an exemplary angular bin (as specified in bottom left), we show collected CERESmeasured TOA SW reflectances ( $y$-axis) against cloud-top effective radii ( $x$-axis; MODIS-retrieved mean value across each CERES footprint); both transformed through the natural logarithm. Colors explain the inferred amount of cloud-topped water vapor. Produced linear model (colored lines and open triangles; Equation (6)) - forming the basis for ADMs—captured the general darkening with larger droplet sizes (predicted for 5 to $25 \mu \mathrm{m}$ ) and with higher levels of cloud-topped moisture (predicted for 0,15 , and $30 \mathrm{~kg} \mathrm{~m}^{-2}$ ). Following the CERES methodology, the average reflectance in this angular bin was represented by the black dot.

\section{Results}

Empirical ADMs allow us to estimate instantaneous TOA fluxes from satellite broadband radiometry. State-of-the-art shortwave ADMs (referred to as "CERES SSF 4" ADMs [15]) over cloudy scenes are sensitive to cloud fraction $f$, cloud optical depth $\tilde{\tau}$, and cloud phase. In this study, we examined whether ADMs should also be sensitive to the cloud micro-physical structure and amount of absorbing atmospheric gas above the cloud layer.

We generated alternative ADMs (referred to as "refined ADMs", Section 2.3), using CERES SSF 4 data (Section 2.1, years 2000-2005), including CERES-observed TOA SW reflectances as well as collocated MODIS-retrieved cloud-top effective radius and estimated cloud-topped water vapor (Section 2.2). As shown in Section 2.1, we restricted ourselves to fully overcast, horizontally homogeneous, low-level, and single-level clouds of optical thickness 10 and added simulated reflectances to angular bins in case of insufficient observations.

Refined ADMs show a marked difference in anisotropy across several cloud-top effective radii (Figure 5, top), predominantly around the cloud bow and cloud glory. A higher cloud glory intensity for smaller droplets and an outward shift (in scattering angle) of cloud bow intensity with larger droplet size is in line with Mie-calculated phase functions (Figure 1). For an $R_{e}$ of $10 \mu \mathrm{m}$, anisotropies from refined ADMs agreed well with those from CERES SSF 4. Samples collected for this study showed median $R_{e}$ around $10 \mu \mathrm{m}$ in most angular bins (9.1-15.3 $\mu \mathrm{m}$ at $\theta_{s} \approx 29^{\circ}$, Table 2$)$. We believe that CERES ADM construction used samples of similar characteristics and therefore produced anisotropies reflecting median conditions. For higher levels of cloud-topped water vapor (Figure 5, bottom), we observed an increase in anisotropy at lower viewing zenith angles and a decrease in anisotropy at higher $\theta_{v}$. Table 3 summarizes the spread in anisotropy for various illumination geometries. Anisotropy variations due to effective radii (2.9-8.0\%) were generally larger than variations due to cloud-topped 
moisture (1.3-6.4\%). The uncertainty in anisotropy (based on reflectance residuals of linear models) was of similar order of magnitude (3.2-5.3\%) for variations due to effective radii and variations due to cloud-topped moisture. By reproducing the CERES approach (exemplarily shown in Figure 4 as black dot) and extracting reflectance residuals, we approximated a corresponding CERES uncertainty. Compared to CERES ADMs, uncertainties of refined ADMs were smaller by a factor 1.2-1.7.
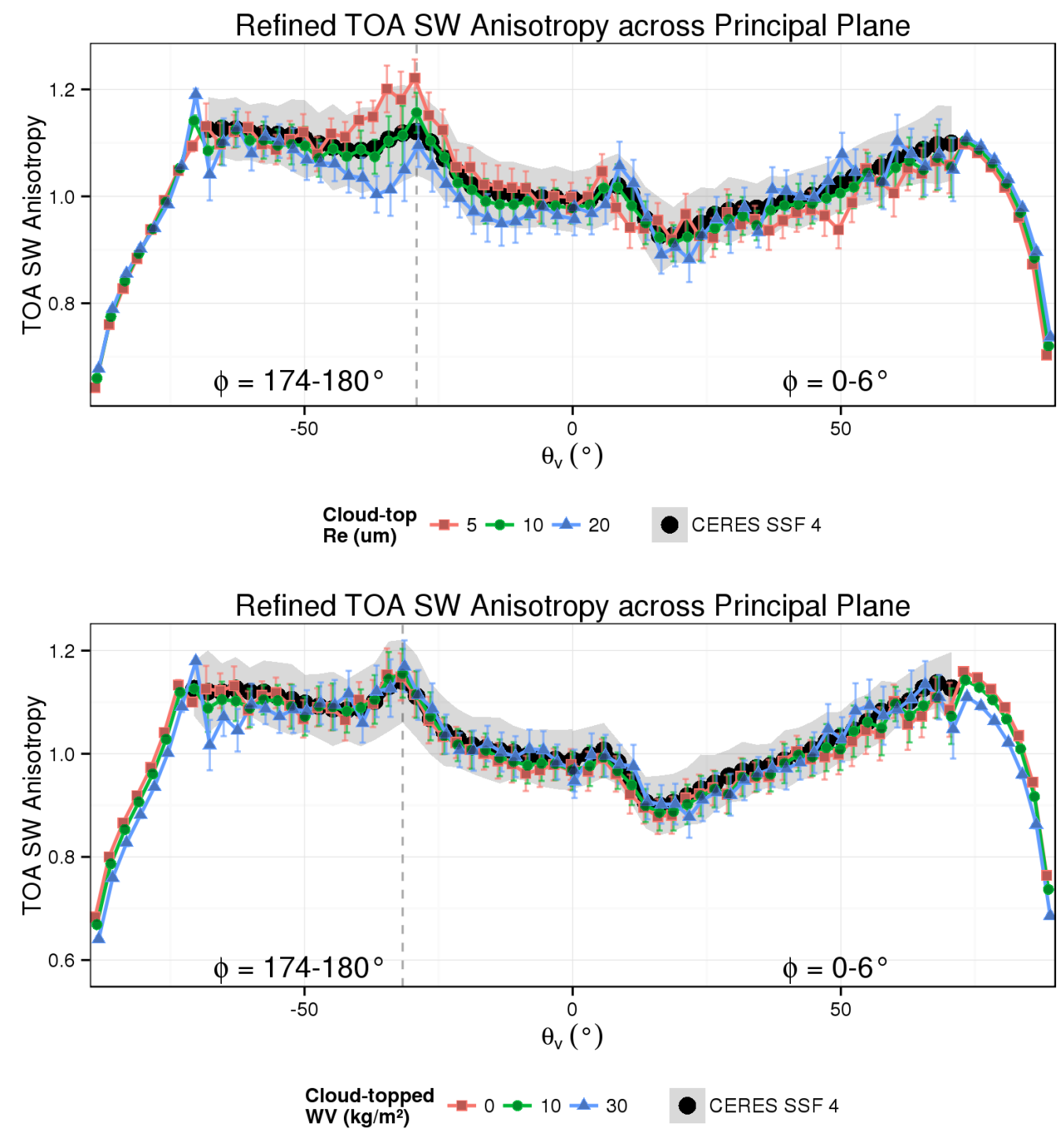

Figure 5. TOA SW anisotropy of refined ADMs at various cloud-top effective radii (top, at a $\theta_{S}$ of $29^{\circ}$ and a steady cloud-topped water vapor of $4 \mathrm{~kg} \mathrm{~m}^{-2}$ ) and levels of cloud-topped water vapor (bottom, at a $\theta_{S}$ of $32^{\circ}$ and a steady cloud-top effective radius of $\left.10 \mu \mathrm{m}\right)$. Colors indicate respective scenarios. Black dots mark TOA SW anisotropy of CERES SSF 4 . Error bars were based on reflectance residuals of linear models propagated into TOA albedo and TOA anisotropy. To obtain corresponding uncertainties for CERES (grey shade), we mimicked the CERES approach and obtained reflectance residuals. Grey dashed lines indicate the cloud glory position.

Refined and CERES ADMs should produce different flux estimates, especially for departures from median conditions (e.g., small and large droplet size distributions). To quantify flux deviations, we took mean reflectances of refined models for three $R_{e}$, three $\theta_{s}$, and a fixed cloud-topped water vapor, and applied both refined and CERES SSF 4 ADMs. A radiance $\hat{I}$ was produced from a reflectance through $\hat{I}=\hat{\rho} S \cos \theta_{s}$, where $S$ is the solar constant. 
$\Delta F\left(\theta_{s}\right)=\pi \hat{I}_{\text {refined }}\left(\theta_{s}, \theta_{v}, \phi, R_{e}, C T W V\right)\left(\frac{1}{R_{\text {refined }}\left(\theta_{s}, \theta_{v}, \phi, R_{e}, C T W V\right)}-\frac{1}{R_{\text {CERES }}\left(\theta_{s}, \theta_{v}, \phi\right)}\right)$

Table 3. A $\theta_{S}$-resolved overview of the anisotropy spread due to extremes in cloud-top effective radius (Column 2 displays the median absolute difference of anisotropy at $25 \mu \mathrm{m}$ and anisotropy at $5 \mu \mathrm{m}$ normalized by the anisotropy at $10 \mu \mathrm{m}$ at a steady cloud-topped water vapor of $4 \mathrm{~kg} \mathrm{~m}^{-2}$ ) and cloud-top water vapor (Column 3 displays the median absolute difference of anisotropy at $32 \mathrm{~kg} \mathrm{~m}^{-2}$ minus anisotropy at $0 \mathrm{~kg} \mathrm{~m}^{-2}$ normalized by the anisotropy at $16 \mathrm{~kg} \mathrm{~m}^{-2}$ at a steady cloud-top effective radius of $10 \mu \mathrm{m}$ ). We also show estimated anisotropy uncertainties of refined ADMs (Column 4), CERES SSF 4 ADMs (Column 5), and their ratio (Column 6). Uncertainties were produced as laid out in Figure 5 and in the text.

\begin{tabular}{|c|c|c|c|c|c|}
\hline \multirow[b]{3}{*}{$\theta_{s}\left({ }^{\circ}\right)$} & \multicolumn{2}{|c|}{ Median Anisotropy } & \multicolumn{2}{|c|}{ Median Anisotropy } & \multirow{3}{*}{$\begin{array}{c}\text { Median Ratio } \\
\text { CERES/ } \\
\text { Refined }\end{array}$} \\
\hline & \multicolumn{2}{|c|}{ Spread (\%) } & \multicolumn{2}{|c|}{ Uncertainties (\%) } & \\
\hline & Cloud-Top $R_{e}$ & Cloud-Topped WV & Refined & CERES-Like & \\
\hline 16.2 & 3.9 & 2.0 & 3.2 & 6.0 & 1.7 \\
\hline 18.8 & 3.9 & 1.9 & 3.7 & 5.9 & 1.5 \\
\hline 21.4 & 3.5 & 1.6 & 4.0 & 6.1 & 1.5 \\
\hline 23.9 & 3.2 & 1.5 & 4.0 & 6.0 & 1.5 \\
\hline 26.5 & 2.9 & 1.3 & 4.0 & 5.7 & 1.4 \\
\hline 29.1 & 2.9 & 1.3 & 4.1 & 5.7 & 1.4 \\
\hline 31.7 & 3.1 & 1.3 & 4.2 & 5.7 & 1.4 \\
\hline 34.3 & 3.2 & 1.3 & 4.3 & 5.6 & 1.3 \\
\hline 36.9 & 3.3 & 1.5 & 4.4 & 5.5 & 1.2 \\
\hline 39.5 & 3.3 & 1.3 & 4.5 & 5.3 & 1.2 \\
\hline 42.1 & 3.3 & 1.5 & 4.5 & 5.3 & 1.2 \\
\hline 44.7 & 2.9 & 1.5 & 4.4 & 5.4 & 1.2 \\
\hline 47.3 & 3.6 & 1.6 & 4.2 & 5.3 & 1.2 \\
\hline 49.9 & 3.7 & 1.5 & 4.0 & 5.2 & 1.3 \\
\hline 52.4 & 3.2 & 1.7 & 4.0 & 5.2 & 1.3 \\
\hline 55.0 & 3.8 & 1.8 & 3.9 & 5.2 & 1.3 \\
\hline 57.6 & 4.5 & 2.0 & 3.7 & 5.1 & 1.4 \\
\hline 60.2 & 4.7 & 1.9 & 3.6 & 5.0 & 1.4 \\
\hline 62.8 & 5.0 & 2.1 & 3.4 & 4.9 & 1.4 \\
\hline 65.4 & 5.6 & 2.7 & 3.4 & 4.9 & 1.4 \\
\hline 68.0 & 5.4 & 2.6 & 3.4 & 4.8 & 1.4 \\
\hline 70.6 & 6.2 & 2.9 & 3.4 & 4.7 & 1.4 \\
\hline 73.2 & 6.7 & 3.4 & 3.3 & 4.6 & 1.3 \\
\hline 75.8 & 6.8 & 3.7 & 3.4 & 4.7 & 1.3 \\
\hline 78.3 & 7.0 & 4.3 & 3.4 & 4.8 & 1.4 \\
\hline 80.9 & 8.0 & 6.4 & 5.3 & 6.4 & 1.2 \\
\hline
\end{tabular}

Figure 6 shows flux deviations between ADMs (computed according to Equation (7)) of up to $20 \mathrm{~W} \mathrm{~m}^{-2}$. For $R_{e}$ of 5 and $20 \mu \mathrm{m}$, these deviations were located in the forward scattering direction ( $\phi$ within $0-45^{\circ}$ ) and again in the direct backscatter (cloud bow and glory). For an $R_{e}$ of $10 \mu \mathrm{m}$, differences were mostly within $10 \mathrm{~W} \mathrm{~m}^{-2}$ and showed a general positive bias. We suspect that employed simulations (predominantly at $\theta_{v}$ of $70^{\circ}$ and higher), which were free of horizontal heterogeneity or 3D effects, produced rather higher reflectances compared to observations. In effect, albedo was slightly overestimated and anisotropies at $\theta_{v}$ lower than $70^{\circ}$ were underestimated (by about $-0.98 \%$ at an $\theta_{s}$ of $29^{\circ}$ for $\theta_{v}$ within $0-70^{\circ}$, cloud-top $R_{e}$ of $10 \mu \mathrm{m}$, and CTWV of $4 \mathrm{~kg} \mathrm{~m}^{-2}$ ).

To facilitate a fairer comparison and to avoid further analysis involving an anisotropy bias, we reproduced CERES SSF estimates (referred to as "CERES-like" ADMs). In addition to the footprints shown in Table 1, we extracted all CERES footprints of the years 2000-2005 which satisfied $f \tilde{\tau} \approx 10$ and 
consisted only of liquid condensate, roughly quadrupling the number of samples. As for refined ADMs, we supplemented angular bins which lacked sufficient CERES observations with simulations. Instead of supplementing an angular bin with all simulated reflectances (i.e., one reflectance from each cloud scenario and moisture profile), we sampled from simulations such that the distribution in cloud-top $R_{e}$ and their level of cloud-topped water vapor corresponded to respective distribution and level of CERES observations within the same $\theta_{s}$ interval. Since footprints had near constant $f \tilde{\tau}$, we skipped the sigmoidal fitting (Section 2.3) and simply averaged reflectances per bin. Resulting CERES-like anisotropies compared well with original CERES SSF estimates, and-as expected from the use of simulations beyond $\theta_{v}$ of $70^{\circ}$-were also biased by about $-0.98 \%$ (at $\theta_{s}$ of $29^{\circ}$ for $\theta_{v}$ within $0-70^{\circ}$ ). We recomputed theoretical flux deviations using refined and CERES-like ADMs and found the positive bias successfully removed for a cloud-top $R_{e}$ of $10 \mu \mathrm{m}$, as shown in Figure 7. Remaining residuals were mostly within $5 \mathrm{~W} \mathrm{~m}^{-2}$. We found that gathered samples increased in CTWV with lower $\theta_{S}$ (Table 2) and reached angular bin medians of up to $16.3 \mathrm{~kg} \mathrm{~m}^{-2}$ (at $\theta_{s}$ of $29^{\circ}$ ). Again, CERES-like ADM construction could have been subject to such sampling and therefore produced ADMs fit to moisture levels higher than $4 \mathrm{~kg} \mathrm{~m}^{-2}$. Observed flux deviations potentially reflected this CERES sampling bias in cloud-topped moisture.

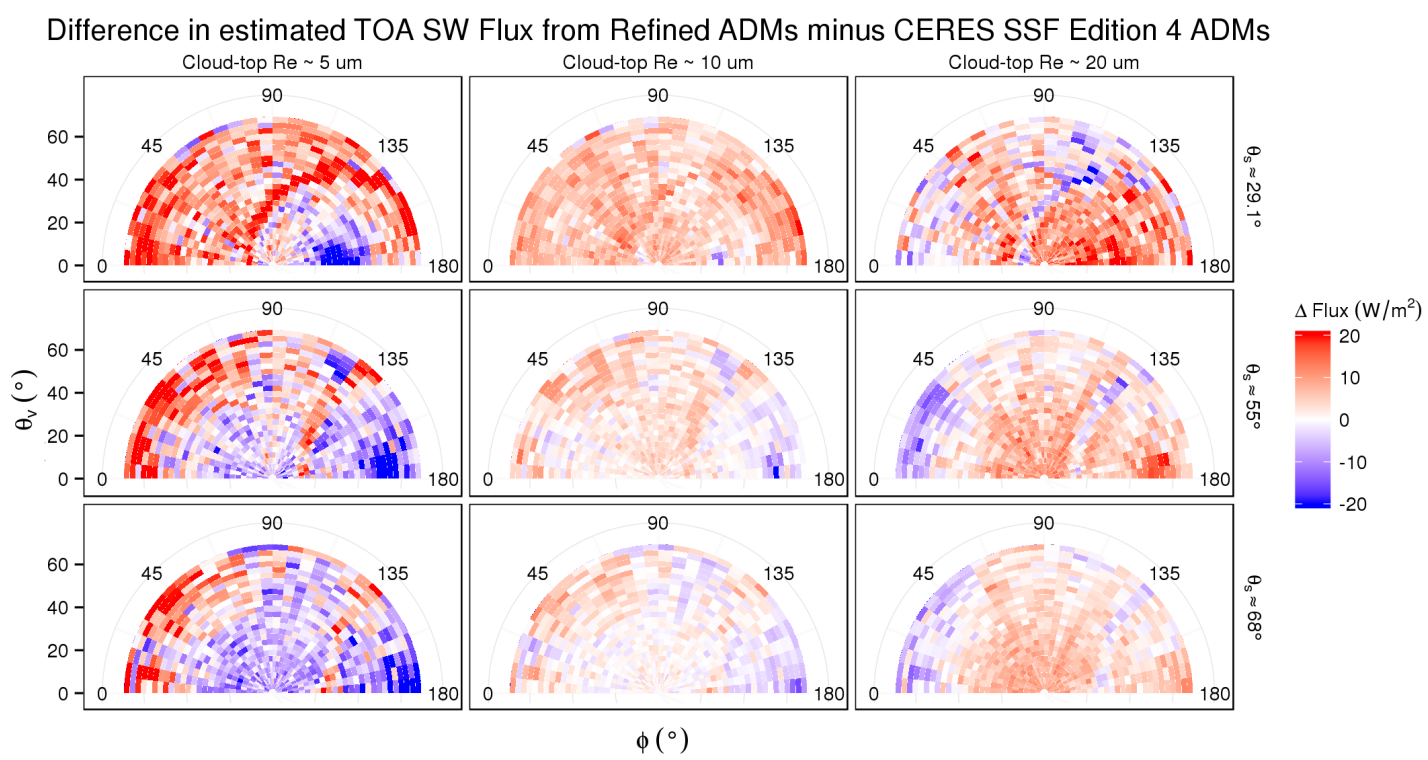

Figure 6. Using TOA SW reflectances predicted from linear models of refined ADMs for three droplet effective radii (varying across panels horizontally) and three $\theta_{s}$ (varying across panels vertically), we applied both refined and CERES SSF 4 ADMs to obtain differences in flux estimates (shown in color). Differences beyond \pm 20 are not further resolved. Linear models were given a constant cloud-topped water vapor of $4 \mathrm{~kg} \mathrm{~m}^{-2}$.

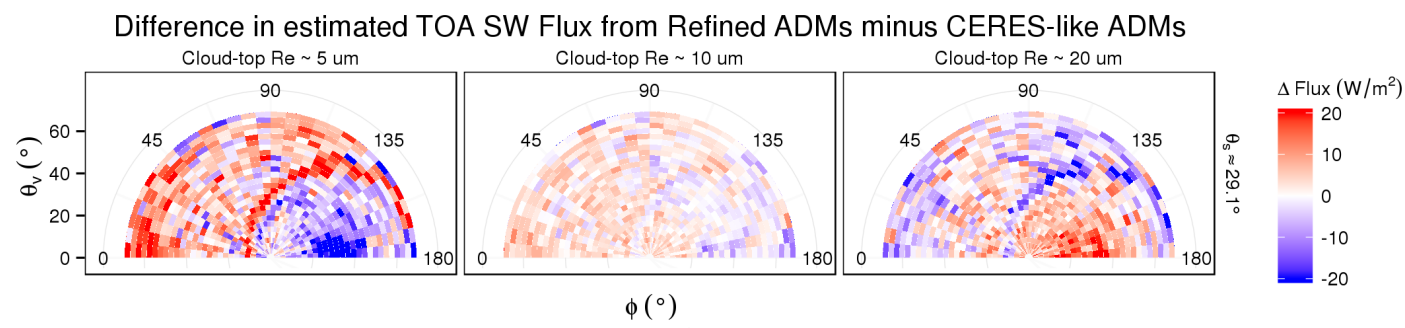

Figure 7. Analogous to Figure 6, we compare refined ADMs with CERES-like ADMs at a $\theta_{S}$ of $29^{\circ}$. 
The CERES cross-track mode collects flux estimates which-when assembled to monthly statistics-provide optimal spatial sampling [30] and allow for benchmark comparisons with global climate model simulations. To examine whether cross-track sampling and the use of refined rather than CERES-like ADMs could produce systematic flux differences, we applied both ADMs to the center months of winter (January) and summer (July) of 2007. Figure 8 shows largely positive biases across the globe, reaching significant large-scale biases of about $1-2 \mathrm{~W} \mathrm{~m}^{-2}$ and local levels of up to $10 \mathrm{~W} \mathrm{~m}^{-2}$.

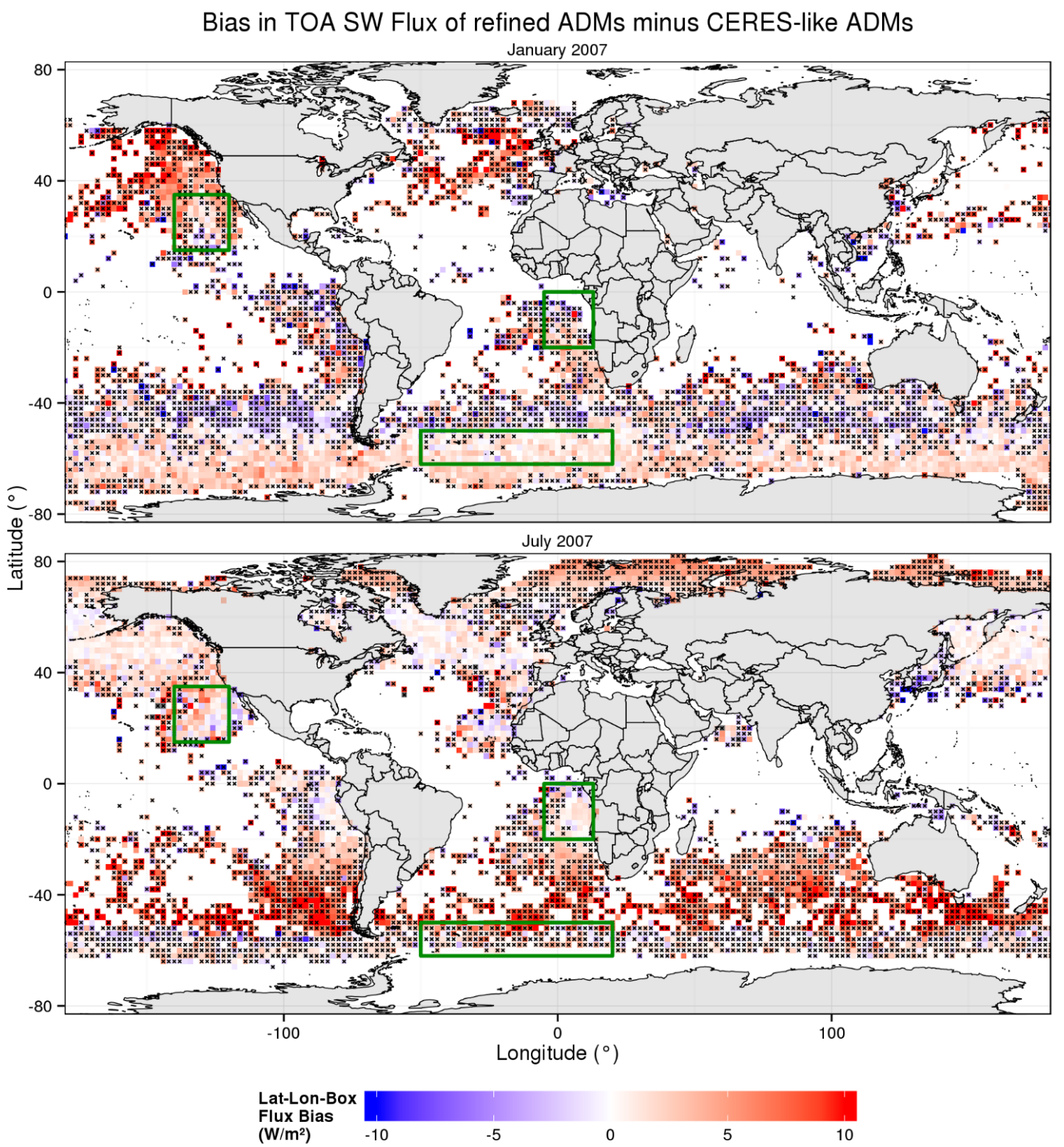

Figure 8. Applied to CERES cross-track measured TOA SW reflectances in January (top) and July (bottom) 2007 over selected conditions ( $\tilde{\tau}$ of 10, 100\% cloud cover, homogeneous conditions), we found that refined angular distribution models produced mostly higher flux estimates than CERES-like ADMs, shown as positive regional flux biases. Insignificant differences (two-sided student $t$-test, $95 \%$ confidence level) over $2 \times 2^{\circ}$ latitude-longitude boxes were marked with black crosses. Anisotropy uncertainties were not considered. 
To investigate whether these large-scale biases were a result of irregular conditions, we examined properties of cross-track samples falling into three regions: SE Atlantic, NE Pacific, and Southern Ocean (highlighted as green rectangles in Figure 8). As shown in Table 4, we found a low median cloud-top effective radius $(8.2 \mu \mathrm{m})$ and low median cloud-topped water vapor $\left(1.6 \mathrm{~kg} \mathrm{~m}^{-2}\right)$ over the SE Atlantic in July. Flux errors of individual samples $\left(-6.4-7.9 \mathrm{~W} \mathrm{~m}^{-2}\right)$ led to median flux deviation of $0.9 \mathrm{~W} \mathrm{~m}^{-2}$. We found slightly larger median flux differences $\left(1.2 \mathrm{~W} \mathrm{~m}^{-2}\right)$ in January over the Southern Ocean. However, the distribution of cloud-top effective radius (a median of $10.5 \mu \mathrm{m}$ ) and cloud-topped moisture (a median of $5.9 \mathrm{~kg} \mathrm{~m}^{-2}$ ) appeared ordinary. We believe that deviations in cloud-top effective radius $(7.2-16.2 \mu \mathrm{m})$ and cloud-topped moisture $\left(2.2-14.1 \mathrm{~kg} \mathrm{~m}^{-2}\right)$ from median conditions paired with a variety of viewing and illumination geometries created flux deviations $\left(-6.0-7.0 \mathrm{~W} \mathrm{~m}^{-2}\right)$ which failed to cancel out to zero.

Table 4. We present median conditions (in $\theta_{s}$, cloud-top effective radius, and cloud-topped water vapor) and median flux errors together with their 5th and 95th percentiles (in parenthesis) for three selected regions (SE Atlantic $\left(20^{\circ} \mathrm{S}-0^{\circ} \mathrm{N}, 5^{\circ} \mathrm{W}-13^{\circ} \mathrm{E}\right)$, NE Pacific $\left(15^{\circ} \mathrm{N}-35^{\circ} \mathrm{N}, 140^{\circ} \mathrm{W}-120^{\circ} \mathrm{W}\right)$, and Southern Ocean $\left(62^{\circ} \mathrm{S}-50^{\circ} \mathrm{S}, 50^{\circ} \mathrm{W}-20^{\circ} \mathrm{E}\right)$ as shown in Figure 8 ) and two calendar months (January and July of 2007). Asterisks mark significant differences identified in Figure 8.

\begin{tabular}{|c|c|c|c|c|c|c|}
\hline & \multicolumn{2}{|c|}{ SE Atlantic } & \multicolumn{2}{|c|}{ NE Pacific } & \multicolumn{2}{|c|}{ Southern Ocean } \\
\hline & January & July & January & July & January & July \\
\hline No. of footprints & 602 & 2286 & 655 & 2376 & 4474 & 1004 \\
\hline Solar Zenith Angle $\left({ }^{\circ}\right)$ & $26.6(17.4-34.6)$ & $41.7(34.2-49.8)$ & $54.8(44.7-59.7)$ & $19.0(10.4-27.9)$ & $44.0(37.1-52.3)$ & $84.7(75.7-86.2)$ \\
\hline Cloud-topped Water Vapour $\left(\mathrm{kg} \mathrm{m}^{-2}\right)$ & $16.1(5.5-29.0)$ & $1.6(0.0-15.2)$ & $0.0(0.0-8.3)$ & $11.6(1.9-32.5)$ & $5.9(2.2-14.1)$ & $0.5(0.0-5.9)$ \\
\hline TOA SW Flux Difference $\left(\mathrm{W} \mathrm{m}^{-2}\right)$ & $1.5(-7.3-12.3)$ & $0.9 *(-6.4-7.9)$ & $2.4(-3.3-9.9)$ & $0.7 *(-9.6-12.8)$ & $1.2 *(-6.0-7.7)$ & $1.1(-3.0-10.9)$ \\
\hline
\end{tabular}

We repeated the analysis with linear models only dependent on effective radius (of the form: $\left.\ln \rho_{o}\left(\theta_{s}, \theta_{v}, \phi\right)=a+b \cdot \ln R_{e}\right)$ and found similar biases; in part reducing the median difference to CERES-like ADMs (Southern Ocean January: $0.6 \mathrm{~W} \mathrm{~m}^{-2}$; SE Atlantic July: $-0.1 \mathrm{~W} \mathrm{~m}^{-2}$ ) and in part increasing it (NE Pacific July: $2.3 \mathrm{~W} \mathrm{~m}^{-2}$ ).

In summary, we show that TOA SW anisotropies of refined ADMs captured departures in cloud-top effective radius and cloud-topped water vapor from respective median conditions. Using mean empirical reflectances of extreme cloud droplet size distributions (cloud-top effective radii of 5 and $20 \mu \mathrm{m}$ ) and comparing CERES ADMs, which were insensitive to such extremes, with refined ADMs, we found deviations in estimated fluxes of up to $20 \mathrm{~W} \mathrm{~m}^{-2}$ at particular viewing and illuminations geometries. When applied to CERES cross-track observations-serving radiation budget climatologies - we demonstrated that the choice of ADM could introduce significant large-scale biases of $1-2 \mathrm{~W} \mathrm{~m}^{-2}$, locally reaching levels of up to $10 \mathrm{~W} \mathrm{~m}^{-2}$. In part, we could attribute large-scale biases to regions of persistently small cloud-top effective radii and low cloud-topped water vapor.

\section{Discussion}

Current ADMs over cloudy scenes have been designed to change with cloud optical thickness and cloud phase. However, a sensitivity towards cloud droplet size and cloud-topped water vapor has not been considered. We show that TOA SW anisotropy changes substantially in situations deviating from median conditions (e.g., much smaller or larger effective radii than $10 \mu \mathrm{m}$ ) which could ultimately lead to the introduction of regional flux biases in monthly means. We identified anisotropy driving factors which should be considered in future ADMs.

We believe that observed regional differences in TOA SW fluxes are a result of a sampling bias. Such bias stems from the fact that individual samples rarely meet ADM median conditions for factors impacting anisotropy (such as cloud effective radius and cloud-topped moisture). Moreover, regional samples can deviate from the median systematically (e.g., stratocumulus clouds near continents are more likely to contain larger cloud droplet number concentrations leading to generally smaller droplet sizes). Alternatively, regional samples can have a temporally shifting deviation from median 
conditions as a changing climate might produce a progressively warmer and moister atmosphere as well as additional cloud condensation nuclei. However, even for regions which meet median conditions (and show a distribution around it), compensation of flux errors (under- and overestimating equally to reach correct monthly means) cannot be guaranteed, as shown in the example "Southern Ocean". It is the nature of polar orbiting, such as Aqua and Terra, or geostationary satellites, such as the Meteosat series, to perceive regions such that $\theta_{s}$ are co-occurring with certain combinations of $\theta_{v}$ and $\phi$. To reach a perfect compensation, one needed to capture an underestimated $R_{e}$ (e.g., $15 \mu \mathrm{m}$; provided that ADMs represent $10 \mu \mathrm{m}$ as median condition) where there had been an overestimation of $R_{e}$ (e.g., $5 \mu \mathrm{m}$ ) before under identical viewing and illumination geometry.

Most regional flux biases were positive (up to $10 \mathrm{~W} \mathrm{~m}^{-2}$ ). Could stratocumulus clouds be more reflective than previously reported? Global climate models persistently produce "too-few-too-bright" low-level clouds [4] and show regional biases to CERES EBAF, such as the AM4.0 (atmosphere model) of about $20 \mathrm{~W} \mathrm{~m}^{-2}$ [31]. Our samples represent a small portion of all low-level cases. Future work should incorporate footprints of other cloud fractions and cloud optical thicknesses to obtain a more representative picture.

Lastly, improved instantaneous flux from refined ADMs estimates should benefit closure assessment experiments such as the future EarthCARE mission [32]. The foreseen broadband radiometer (BBR) will observe SW radiances at three along-track viewing angles (nadir-viewing and $\theta_{v} \approx 55^{\circ}$ forward and backward viewing) and, correspondingly, produce three SW flux estimates. In contrast to the CERES cross-track mode, BBR viewing geometries will be much closer to the principal plane and therefore more sensitive to cloud-top effective radii. We expect a better agreement in estimated fluxes across the three along-track views. Future work should verify such consistency of developed ADMs by using multi-viewing instruments such as MISR [33].

Author Contributions: Conceptualization, F.T., R.P. and C.D.; Methodology, F.T., C.K.C.H., R.P., S.T., and J.F.; Software, F.T., R.P. and J.F.; Validation, F.T. and C.D.; Formal Analysis, F.T.; Investigation, F.T.; Resources, R.P. and J.F.; Data Curation, F.T.; Writing-Original Draft Preparation, F.T.; Writing-Review and Editing, F.T., R.P., C.D., C.K.C.H., and S.T.; Visualization, F.T. and S.T.; Supervision, F.T. and J.F.; Project Administration, J.F.; and Funding Acquisition, J.F. and C.D.

Funding: This research was funded by ESA contract number 4000112019/14/NL/CT.

Acknowledgments: We thank Ralf Bennartz, Bjorn Stevens and Nicole Docter for helpful discussion. This work was possible through funding within the ESA contract 4000112019/14/NL/CT. The authors would also like to thank the anonymous reviewers for their constructive and helpful comments, and to the Atmospheric Sciences Data Center at the National Aeronautics and Space Administration, Langley Research Center, for providing them with the Clouds and the Earth's Radiant Energy System Single Scanning Footprint TOA/Surface Fluxes and Clouds data product.

Conflicts of Interest: The authors declare no conflict of interest. The founding sponsors had no role in the design of the study; in the collection, analyses, or interpretation of data; in the writing of the manuscript, and in the decision to publish the results.

\section{References}

1. Ramanathan, V.; Cess, R.D.; Harrison, E.F.; Minnis, P.; Barkstrom, B.R.; Ahmad, E.; Hartmann, D. CloudRadiative Forcing and Climate: Results from the Earth Radiation Budget Experiment. Science 1989, 243, 57-63. [CrossRef] [PubMed]

2. Wood, R. Stratocumulus Clouds. Mon. Weather Rev. 2012, 140, 2373-2423. [CrossRef]

3. Bony, S.; Dufresne, J.L. Marine boundary layer clouds at the heart of tropical cloud feedback uncertainties in climate models. Geophys. Res. Lett. 2005, 32. [CrossRef]

4. Nam, C.; Bony, S.; Dufresne, J.L.; Chepfer, H. The 'too few, too bright' tropical low-cloud problem in CMIP5 models. Geophys. Res. Lett. 2012, 39. [CrossRef]

5. Twomey, S. The Influence of Pollution on the Shortwave Albedo of Clouds. J. Atmos. Sci. 1977, 34, 1149-1152. [CrossRef]

6. Gryspeerdt, E.; Quaas, J.; Bellouin, N. Constraining the aerosol influence on cloud fraction. J. Geophys. Res. Atmos. 2016, 121, 3566-3583. [CrossRef] 
7. Costantino, L.; Bréon, F.M. Analysis of aerosol-cloud interaction from multi-sensor satellite observations. Geophys. Res. Lett. 2010, 37. [CrossRef]

8. Painemal, D.; Kato, S.; Minnis, P. Boundary layer regulation in the southeast Atlantic cloud microphysics during the biomass burning season as seen by the A-train satellite constellation. J. Geophys. Res. Atmos. 2014, 119, 11288-11302. [CrossRef]

9. Goren, T.; Rosenfeld, D. Satellite observations of ship emission induced transitions from broken to closed cell marine stratocumulus over large areas. J. Geophys. Res. Atmos. 2012, 117. [CrossRef]

10. Christensen, M.W.; Stephens, G.L. Microphysical and macrophysical responses of marine stratocumulus polluted by underlying ships: Evidence of cloud deepening. J. Geophys. Res. Atmos. 2011, 116. [CrossRef]

11. Toll, V.; Christensen, M.W.; Gassó, S.; Bellouin, N. Volcano and Ship Tracks Indicate Excessive Aerosol-Induced Cloud Water Increases in a Climate Model. Geophys. Res. Lett. 2017, 44, 12492-12500. [CrossRef] [PubMed]

12. Ackerman, A.S.; Kirkpatrick, M.P.; Stevens, D.E.; Toon, O.B. The impact of humidity above stratiform clouds on indirect aerosol climate forcing. Nature 2004, 432, 1014-1017. [CrossRef] [PubMed]

13. Viollier, M.; Standfuss, C.; Chomette, O.; Quesney, A. Top-of-Atmosphere Radiance-to-Flux Conversion in the SW Domain for the ScaRaB-3 Instrument on Megha-Tropiques. J. Atmos. Ocean. Technol. 2009, 26, 2161-2171. [CrossRef]

14. Dewitte, S.; Gonzalez, L.; Clerbaux, N.; Ipe, A.; Bertrand, C.; Paepe, B.D. The Geostationary Earth Radiation Budget Edition 1 data processing algorithms. Adv. Space Res. 2008, 41, 1906-1913. [CrossRef]

15. Su, W.; Corbett, J.; Eitzen, Z.; Liang, L. Next-generation angular distribution models for top-of-atmosphere radiative flux calculation from CERES instruments: Methodology. Atmos. Meas. Tech. 2015, 8, 611-632. [CrossRef]

16. Wielicki, B.A.; Barkstrom, B.R.; Harrison, E.F.; Lee, R.B., III; Smith, G.L.; Cooper, J.E. Clouds and the Earth's Radiant Energy System (CERES): An Earth Observing System Experiment. Bull. Am. Meteorol. Soc. 1996, 77, 853-868. [CrossRef]

17. Minnis, P.; Sun-Mack, S.; Young, D.F.; Heck, P.W.; Garber, D.P.; Chen, Y.; Spangenberg, D.A.; Arduini, R.F.; Trepte, Q.Z.; Smith, W.L.; et al. CERES Edition-2 Cloud Property Retrievals Using TRMM VIRS and Terra and Aqua MODIS Data_Part I: Algorithms. IEEE Trans. Geosci. Remote Sens. 2011, 49, 4374-4400. [CrossRef]

18. Barker, H.W.; Wiellicki, B.A.; Parker, L. A Parameterization for Computing Grid-Averaged Solar Fluxes for Inhomogeneous Marine Boundary Layer Clouds. Part II: Validation Using Satellite Data. J. Atmos. Sci. 1996, 53, 2304-2316. [CrossRef]

19. Kato, S.; Rose, F.G.; Charlock, T.P. Computation of Domain-Averaged Irradiance Using Satellite-Derived Cloud Properties. J. Atmos. Ocean. Technol. 2005, 22, 146-164. [CrossRef]

20. Hollstein, A.; Fischer, J. Radiative transfer solutions for coupled atmosphere ocean systems using the ma trix operator technique. J. Quant. Spectrosc. Radiat. Transf. 2012, 113, 536-548. [CrossRef]

21. Doppler, L.; Preusker, R.; Bennartz, R.; Fischer, J. k-bin and k-IR: k-distribution methods without correlation approximation for $\mathrm{n}$ on-fixed instrument response function and extension to the thermal infrared-Application s to satellite remote sensing. J. Quant. Spectrosc. Radiat. Transf. 2014, 133, 382-395. [CrossRef]

22. Rothman, L.; Gordon, I.; Barbe, A.; Benner, D.; Bernath, P.; Birk, M.; Boudon, V.; Brown, L.; Campargue, A.; Champion, J.P.; et al. The HITRAN 2008 molecular spectroscopic database. J. Quant. Spectrosc. Radiat. Transf. 2009, 110, 533-572. [CrossRef]

23. Hansen, J.E. Multiple scattering of polarized light in a planetary atmosphere. part II: Sunlight reflected by terrestrial water clouds. J. Atmos. Sci. 1971, 28, 1400-1426. [CrossRef]

24. McClatchey, R.A.; Fenn, R.W.; Selby, J.E.A.; Volz, F.E. Optical Properties of the Atmosphere; Technical Report AFCRL-71-0279; Air Force Cambridge Research Laboratories: Bedford, MA, USA, 1971.

25. Brenguier, J.L.; Pawlowska, H.; Schüller, L.; Preusker, R.; Fischer, J.; Fouquart, Y. Radiative Properties of Boundary Layer Clouds: Droplet Effective Radius versus Number Concentration. J. Atmos. Sci. 2000, 57, 803-821. [CrossRef]

26. Bloom, S.; da Silva, A.; Dee, D. Documentation and Validation of the Goddard Earth Observing System (GEOS) Data Assimilation System; Technical Report TM-2005-104606; NASA: Washington, DC, USA, 2005.

27. Bolton, D. The Computation of Equivalent Potential Temperature. Mon. Weather Rev. 1980, 108, 1046-1053. [CrossRef] 
28. Cattani, E.; Costa, M.; Torricella, F.; Levizzani, V.; Silva, A. Influence of aerosol particles from biomass burning on cloud microphysical properties and radiative forcing. Atmos. Res. 2006, 82, 310-327. [CrossRef]

29. Painemal, D.; Minnis, P.; Sun-Mack, S. The impact of horizontal heterogeneities, cloud fraction, and liquid water path on warm cloud effective radii from CERES-like Aqua MODIS retrievals. Atmos. Chem. Phys. 2013, 13, 9997-10003. [CrossRef]

30. Doelling, D.R.; Loeb, N.G.; Keyes, D.F.; Nordeen, M.L.; Morstad, D.; Nguyen, C.; Wielicki, B.A.; Young, D.F.; Sun, M. Geostationary Enhanced Temporal Interpolation for CERES Flux Products. J. Atmos. Ocean. Technol. 2013, 30, 1072-1090. [CrossRef]

31. Zhao, M.; Golaz, J.C.; Held, I.M.; Guo, H.; Balaji, V.; Benson, R.; Chen, J.H.; Chen, X.; Donner, L.J.; Dunne, J.P.; et al. The GFDL Global Atmosphere and Land Model AM4.0/LM4.0: 1. Simulation Characteristics With Prescribed SSTs. J. Adv. Model. Earth Syst. 2018, 10, 691-734. [CrossRef]

32. Illingworth, A.J.; Barker, H.W.; Beljaars, A.; Chepfer, H.; Delanoe, J.; Domenech, C.; Donovan, D.P.; Fukuda, S.; Hirakata, M.; Hogan, R.J.; et al. The EarthCARE Satellite: The next step forward in global measurements of clouds, aerosols, precipitation and radiation. Bull. Am. Meteorol. Soc. 2015, 96, 1311-1332. [CrossRef]

33. Diner, D.J.; Beckert, J.C.; Reilly, T.H.; Bruegge, C.J.; Conel, J.E.; Kahn, R.A.; Martonchik, J.V.; Ackerman, T.P.; Davies, R.; Gerstl, S.A.W.; et al. Multi-angle Imaging SpectroRadiometer (MISR) instrument description and experiment overview. IEEE Trans. Geosci. Remote Sens. 1998, 36, 1072-1087. [CrossRef]

(C) 2018 by the authors. Licensee MDPI, Basel, Switzerland. This article is an open access article distributed under the terms and conditions of the Creative Commons Attribution (CC BY) license (http://creativecommons.org/licenses/by/4.0/). 